\title{
The Insulation Properties of Oil-Impregnated Insulation Paper Reinforced with Nano-TiO
}

\author{
Ruijin Liao, ${ }^{1}$ Cheng Lv, ${ }^{1}$ Lijun Yang, ${ }^{1}$ Yiyi Zhang, ${ }^{1,2}$ Weiqiang Wu, ${ }^{1}$ and Chao Tang ${ }^{3}$ \\ ${ }^{1}$ State Key Laboratory of Power Transmission Equipment \& System Security and New Technology, Chongqing University, \\ Shapingba District, Chongqing 400044, China \\ ${ }^{2}$ FREEDM Systems Center, Department of Electrical and Computer Engineering, North Carolina State University, \\ Raleigh, NC 27606, USA \\ ${ }^{3}$ College of Engineering and Technology, Southwest University, Beibei District, Chongqing 400715, China
}

Correspondence should be addressed to Cheng Lv; lvcheng20050602135@163.com and Yiyi Zhang; yiyizhang.cqu@gmail.com

Received 13 September 2013; Accepted 1 October 2013

Academic Editor: Wenjie Mai

Copyright (c) 2013 Ruijin Liao et al. This is an open access article distributed under the Creative Commons Attribution License, which permits unrestricted use, distribution, and reproduction in any medium, provided the original work is properly cited.

Oil-impregnated insulation paper has been widely used in transformers because of its low cost and desirable physical and electrical properties. However, research to improve the insulation properties of oil-impregnated insulation paper is rarely found. In this paper, nano- $\mathrm{TiO}_{2}$ was used to stick to the surface of cellulose which was used to make insulation paper. After oil-impregnated insulation paper reinforced by nano- $\mathrm{TiO}_{2}$ was prepared, the tensile strength, breakdown strength, and dielectric properties of the oil-impregnated insulation paper were investigated to determine whether the modified paper had a better insulation performance. The results show that there were no major changes in tensile strength, and the value of the breakdown strength was greatly improved from $51.13 \mathrm{kV} / \mathrm{mm}$ to $61.78 \mathrm{kV} / \mathrm{mm}$. Also, the values of the relative dielectric constant, the dielectric loss, and conductivity declined. The discussion reveals that nano- $\mathrm{TiO}_{2}$ plays a major role in the phenomenon. Because of the existence of nano-TiO ${ }_{2}$, the contact interface of cellulose and oil was changed, and a large number of shallow traps were produced. These shallow traps changed the insulation properties of oil-impregnated insulation paper. The results show that the proposed solution offers a new method to improve the properties of oil-impregnated insulation paper.

\section{Introduction}

The power transformer, an important piece of power transmission equipment, is the core component of the power system [1]. Currently, most transformers are oil-immersed transformers, and their insulation is composed of the insulation oil and insulation paper. Insulation paper, which is widely used in oil-immersed transformers, is made of natural cellulose $[2,3]$. Although its use began in the 1890s, natural cellulose insulation paper is still widely used in oil-immersed power transformers, although insulation materials have made significant changes and progress.

Transformer insulation should be developed concurrently with an increase in voltage level. In recent years, much research on insulation oil has been carried out to improve the insulation properties [4-6]. However, research to improve the insulation properties of oil-impregnated insulation paper has been rare.

In the traditional paper industry, various fillers are applied to improve various properties of paper. However, no filler is used in insulation paper. The reason is that the mechanical properties are reduced greatly when using the traditional micron-level filler. Nanotechnology has developed rapidly in recent years, and various nanoscale fillers are used to modify polymers [7-13]. The results of the research show that a small amount of nanofiller has a great impact on the performance of a polymer. In the papermaking industry, nanoscale fillers have also been widely used [14-17]. However, these studies were not related to the properties of insulation paper.

When $\mathrm{TiO}_{2}$ particles are used in papermaking, it is well known that the $\mathrm{TiO}_{2}$ particle can be attached to the cellulose 
surface. After the oil immersion process of insulation paper, the cellulose and $\mathrm{TiO}_{2}$ are wrapped by oil. The unsaturated coordination titanium of the $\mathrm{TiO}_{2}$ surface can capture electron in the oil [18]; the effect may greatly change the insulation properties in oil-impregnated insulation paper. Therefore, nano- $\mathrm{TiO}_{2}$ was chosen to reinforce oil-impregnated insulation paper in this paper. The breakdown strength and dielectric properties of oil-impregnated insulation paper modified by nano- $\mathrm{TiO}_{2}$ were studied for the first time. A mechanism showing that nano- $\mathrm{TiO}_{2}$ improves the insulation properties of insulation paper was discussed.

\section{Experimental}

2.1. Materials. Pulp board (softwood pulp, Taizhou Xinyuan Electrical Equipment, Taizhou, China) used for making insulation paper was beaten to about 400 Canadian standard freeness (CSF) in a valley beater. Nano- $\mathrm{TiO}_{2}$ (95ZX063, Shanghai MaiKun Chemical Company, Shanghai, China, average particle size diameter $<60 \mathrm{~nm}$, relative dielectric constant $\varepsilon r=100 \varepsilon_{0}$, and conductivity $\sigma=1 \times 10^{11} \mathrm{~S} / \mathrm{m}$ ), anhydrous ethanol (analytical pure, ShuangShuang Chemical, Shandong, China), sodium hydroxide (analytical pure, Huludao City Chemical Reagent, Liaoning, China), and silane coupling agent (Z-6030, The United States Dow Corning Corporation, Milrand, MI, USA) were purchased for the experiment. The oil for immersing the insulation paper was conventional transformer mineral oil (numbers 25, Sichuan Chuanrun, Chengdu, China).

2.2. Surface Modification of Nano-TiO ${ }_{2}$. Surface modification must be performed before the nano- $\mathrm{TiO}_{2}$ can be used to reinforce the insulation paper. The surface modification process is as follows.

(1) $50 \mathrm{~g}$ of nano- $\mathrm{TiO}_{2}$ was weighed and placed in a $100^{\circ} \mathrm{C}$ oven for $30 \mathrm{~min}$.

(2) $0.5 \mathrm{~g}$ of silane coupling agent was weighed and put into a beaker.

(3) $100 \mathrm{~mL}$ of anhydrous ethanol was put into the beaker, and the $\mathrm{pH}$ value of the mixed solution was adjusted with sodium hydroxide.

(4) $\mathrm{Nano}-\mathrm{TiO}_{2}$ was added to the mixed solution. Then, the mixed solution was poured into a three-necked flask, and $400 \mathrm{~mL}$ of anhydrous ethanol was added.

(5) The three-necked flask was heated using the water bath method with constant stirring.

(6) After finishing the reaction, the product was placed in a beaker and put into a $100^{\circ} \mathrm{C}$ oven to dry for $24 \mathrm{~h}$.

\subsection{Preparation and Oil Immersion Process of Insulation} Paper. First, the nano- $\mathrm{TiO}_{2}$, which was modified by a silane coupling agent, was dissolved in absolute ethanol $(1: 100 \mathrm{wt} \%)$, and the slurry was homogenized by vigorous agitation with a magnetic stir bar for $10 \mathrm{~min}$. Next, the pulp was diluted to $0.4 \mathrm{wt} \%$ in deionized water, and various $\mathrm{wt} \%$ of nano- $\mathrm{TiO}_{2}$ were added. The mixtures were stirred for

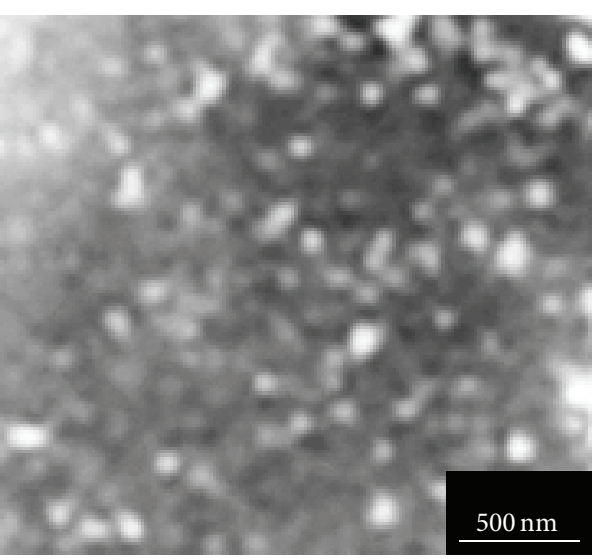

FIGURE 1: SEM images of insulation paper reinforced with nano$\mathrm{TiO}_{2}$ after oil immersion process.

$5 \mathrm{~min}$ at $5000 \mathrm{rpm}$ in a fiber disintegration device and were used to create the insulation paper. Then, each wet insulation paper sample was dried at $105^{\circ} \mathrm{C}$ for 7 min under a vacuum. Insulation paper with a target basis weight of $120 \mathrm{~g} / \mathrm{m}^{2}$ was produced. Lastly, insulation paper was immersed in oil, using the following steps.

(1) The insulation paper was cut into 4 and $8 \mathrm{~cm}$ diameter circles and placed into different glass bottles according to the sample type.

(2) All samples were put into the vacuum chamber and were dried at $90^{\circ} \mathrm{C}$ for $48 \mathrm{~h}$. After that, the temperature of the vacuum chamber was adjusted to $40^{\circ} \mathrm{C}$.

(3) Mineral oil at $40^{\circ} \mathrm{C}$ was infused into the glass bottles in the vacuum chamber to immerse the samples for $24 \mathrm{~h}$.

As shown in Figure 1, the distribution of nano- $\mathrm{TiO}_{2}$ in the oil-impregnated insulation paper is uniform and the average particle size of $\mathrm{TiO}_{2}$ is less than $60 \mathrm{~nm}$.

2.4. Experiment Characterization. After the insulation paper samples were prepared, they were immersed in mineral oil to measure the breakdown strength, density, polarization current, depolarization current (PDC), thermally stimulated depolarization current (TSDC), scanning electron microscopy (SEM), and frequency domain dielectric spectrum (FDS). Some other samples that were not immersed in mineral oil were used to measure tensile strength.

The breakdown strength was measured with homemade equipment according to IEC 60241-1:1998. Electrodes were made from copper. The diameters of the high-voltage (HV) electrode and ground electrode were both $25 \mathrm{~mm}$. Insulation oil was used as the dielectric surrounding the equipment. The test power supply used was HV alternating current power. Its boot speed was $500 \mathrm{~V} / \mathrm{s}$, and its frequency was $50 \mathrm{~Hz}$. The breakdown electric field strength of each sample was measured seven times. The diagram of the equipment used to test the breakdown strength is shown in Figure 2.

Tensile strength was measured with an electronic pull tester (AT-L-2, ANMT Instrument). The tensile speed was 


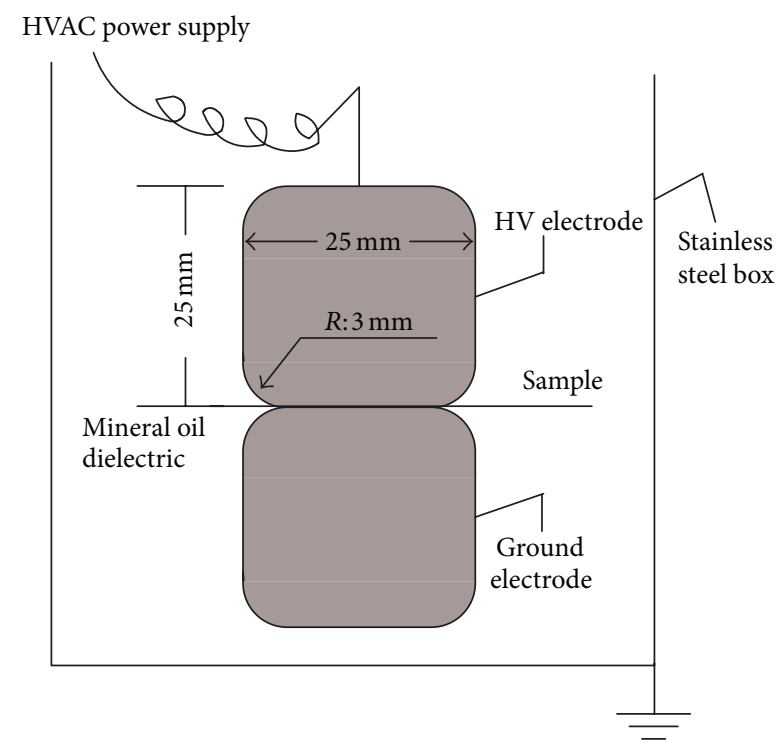

FIGURE 2: Diagram of equipment used to test the breakdown strength.

$10 \mathrm{~mm} / \mathrm{min}$. The length of the samples was $100 \mathrm{~mm}$, and the width was $15 \mathrm{~mm}$. The tensile strength of each sample was measured 10 times.

Dielectric properties under different frequencies $\left(10^{-2}\right.$ to $10^{7} \mathrm{~Hz}$ ) at room temperature were measured by broadband dielectric spectroscopy equipment (Novocontrol concept 80, $\mathrm{GmbH}$, Germany). The oil on the surface of the oil-impregnated insulation paper was cleared before the samples were measured. The measuring electrodes were two copper plates with $4 \mathrm{~cm}$ diameters. The density of the oil-impregnated insulation paper was measured by the Archimedes method.

The polarization and depolarization current analyses were carried out with a PDC-Analyser-1MOD (ALFF Engineering, Switzerland), and the measurement time was set to $5000 \mathrm{~s}$.

Trapping parameters of electrons in the dielectric is determined by using the thermally stimulated depolarization current technique. The experiment was carried out using Novocontrol TSDC equipment. Considering the temperature tolerance of the insulation oil, the test temperature range was set from $-30^{\circ} \mathrm{C}$ to $130^{\circ} \mathrm{C}$.

\section{Results and Discussion}

The nano- $\mathrm{TiO}_{2}$ contents in the insulation paper were $0,1,2$, 3 , and $4 \%$, and they were designated as $\mathrm{P} 0, \mathrm{P} 1, \mathrm{P} 2, \mathrm{P} 3$, and $\mathrm{P} 4$, respectively.

Relations between tensile strength and different nano$\mathrm{TiO}_{2}$ contents in the insulation paper are shown in Figure 3. The tensile strength of insulation paper slightly decreases with increasing nano- $\mathrm{TiO}_{2}$ content in the insulation paper. The tensile strengths of $\mathrm{P} 0, \mathrm{P} 1, \mathrm{P} 2, \mathrm{P} 3$, and $\mathrm{P} 4$ are $8.58 \mathrm{kN} / \mathrm{m}$, $8.56 \mathrm{kN} / \mathrm{m}, 8.52 \mathrm{kN} / \mathrm{m}, 8.55 \mathrm{kN} / \mathrm{m}$, and $8.32 \mathrm{kN} / \mathrm{m}$, respectively.

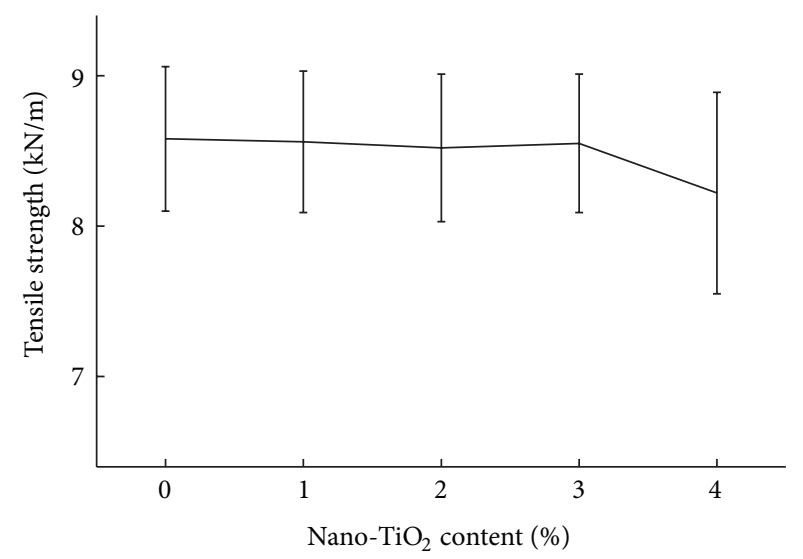

Figure 3: Effect of nano- $\mathrm{TiO}_{2}$ content on the tensile strength of insulation paper.

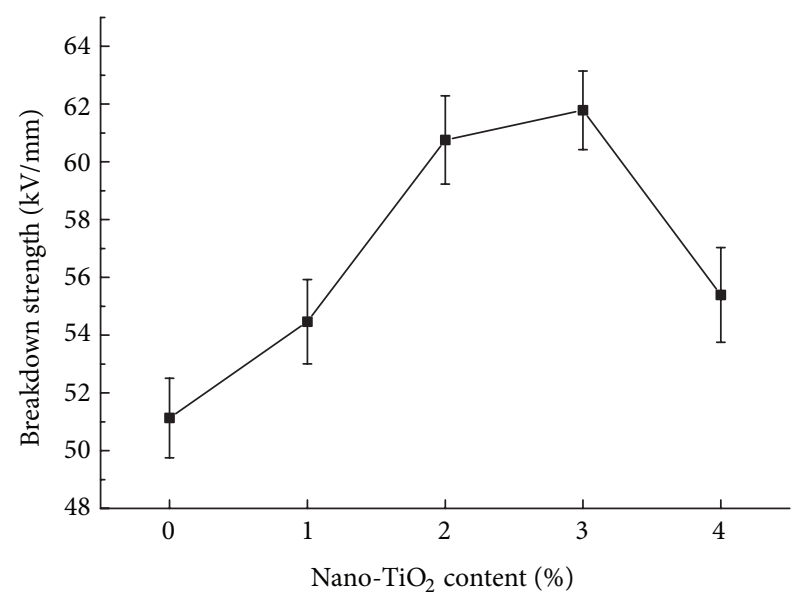

FIGURE 4: Effect of nano- $\mathrm{TiO}_{2}$ content on the breakdown strength of oil-impregnated insulation paper reinforced with nano- $\mathrm{TiO}_{2}$.

From Figure 4, the breakdown strength of oil-impregnated insulation paper significantly increases and then decreases with increasing nano- $\mathrm{TiO}_{2}$ content. When the nano$\mathrm{TiO}_{2}$ content reached $3 \%$, the breakdown strength reached its maximum value of $61.78 \mathrm{kV} / \mathrm{mm}$, while the breakdown strength of $\mathrm{P} 0$ was $51.13 \mathrm{kV} / \mathrm{mm}$. The breakdown strength of P3 increased by $20.83 \%$ compared to that of P0.

When the nano- $\mathrm{TiO}_{2}$ content reached $4 \%$, breakdown strength began to decrease. Therefore, the maximum content was set at $3 \%$ in the following experiments.

The variation of the relative permittivity of oil-impregnated insulation paper reinforced with different nano- $\mathrm{TiO}_{2}$ contents at different frequencies is shown in Figure 5. The trend for the four kinds of samples is similar. The changes in relative permittivity range from $10^{-2} \mathrm{~Hz}$ to $10^{7} \mathrm{~Hz}$. The relative permittivity of oil-impregnated insulation paper reinforced with nano- $\mathrm{TiO}_{2}$ is lower than that of oil-impregnated insulation paper that is not reinforced with nano- $\mathrm{TiO}_{2}$ within the test frequency range. Furthermore, at $50 \mathrm{~Hz}$, the relative permittivity decreases with increasing nano- $\mathrm{TiO}_{2}$ content, and the relative permittivity of $\mathrm{P} 3$ has a minimum value 


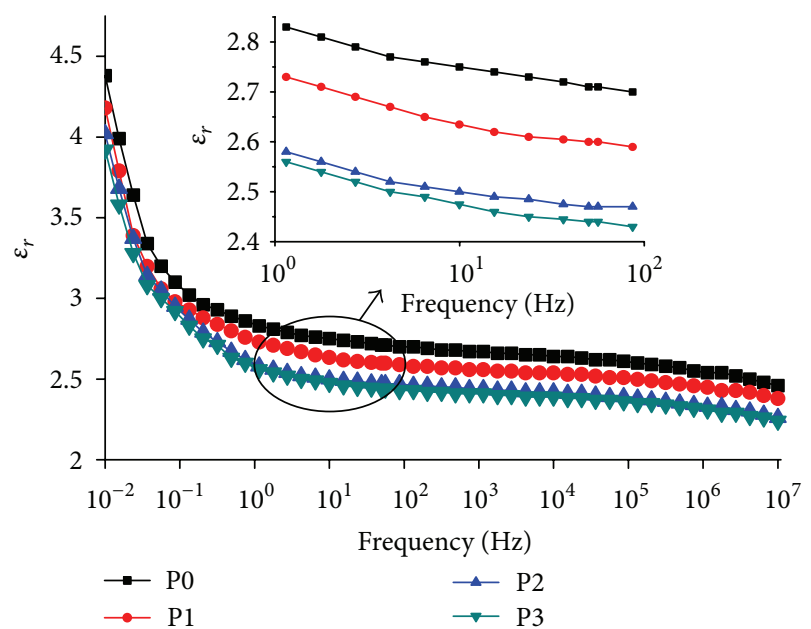

FIGURE 5: Variation of relative permittivity of oil-impregnated insulation paper reinforced with different nano- $\mathrm{TiO}_{2}$ contents at different frequencies.

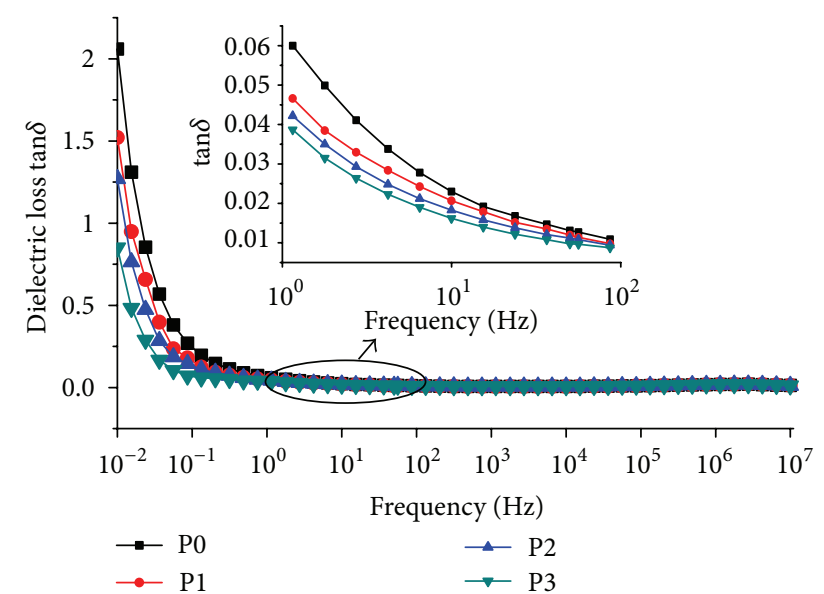

FIGURE 6: Variation of the dielectric loss of oil-impregnated insulation paper reinforced with different nano- $\mathrm{TiO}_{2}$ contents at different frequencies.

of 2.41. The electric field strength distribution of each part of the composite insulation has an inverse correlation with relative permittivity. The relative permittivity of insulation paper is higher than that of insulation oil, and the breakdown strength of insulation oil is lower than that of insulation paper. Therefore, the decrease in relative permittivity is crucial to the improvement of the insulation property of the oil-paper insulation system.

Figure 6 shows the variation of the dielectric loss of oilimpregnated insulation paper reinforced with different nano$\mathrm{TiO}_{2}$ contents at different frequencies, and the trends for the four kinds of samples are similar. The dielectric loss of the four kinds of oil-impregnated insulation paper decreases with increasing frequency. When the nano- $\mathrm{TiO}_{2}$ content increases, the dielectric loss of oil-impregnated insulation paper decreases. There is little difference from $10 \mathrm{~Hz}$ to $10^{7} \mathrm{~Hz}$.

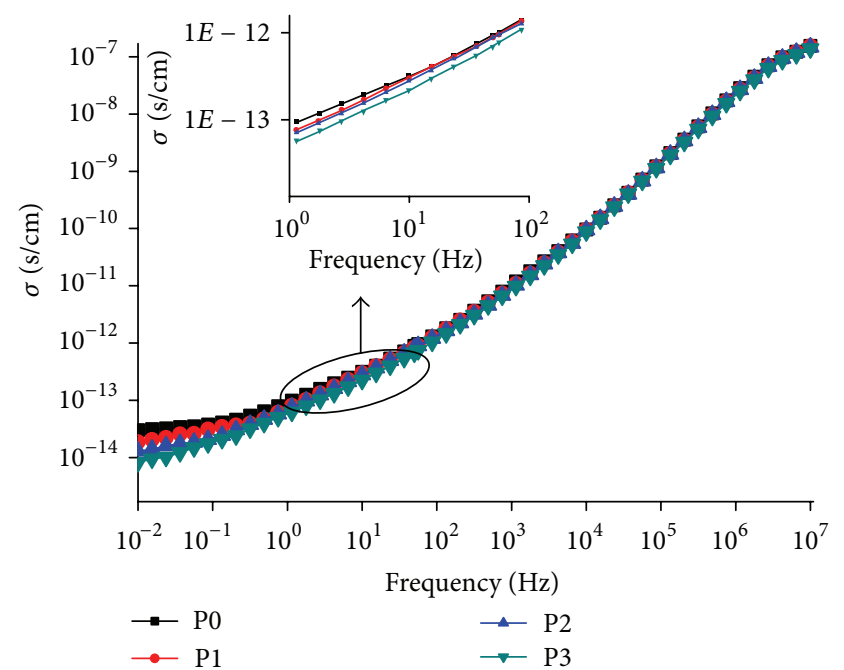

FIGURE 7: Variation of the conductivity of oil-impregnated insulation paper reinforced with different nano- $-\mathrm{TiO}_{2}$ contents at different frequencies.

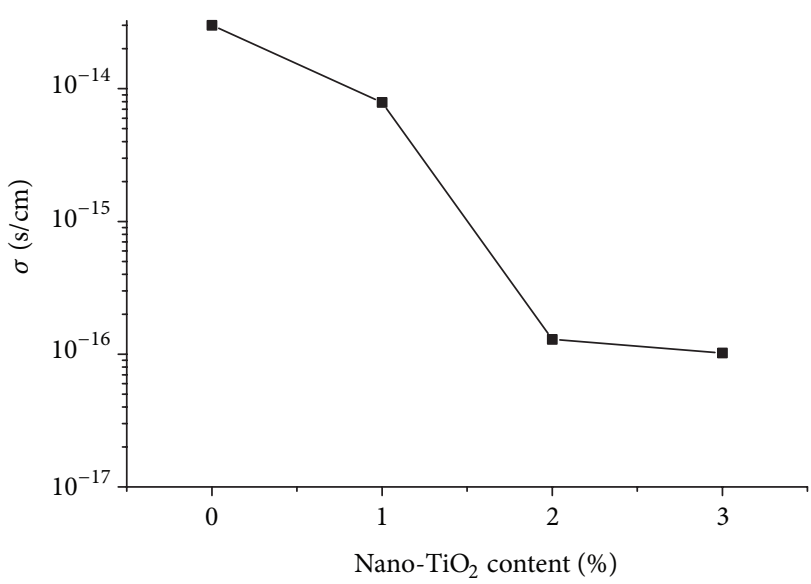

FIGURE 8: Volume conductivity of oil-impregnated insulation paper reinforced with different nano- $\mathrm{TiO}_{2}$ contents (measured under DC).

However, there is a visible difference in the dielectric loss of oil-impregnated insulation paper from $10^{-2} \mathrm{~Hz}$ to $10 \mathrm{~Hz}$.

The variation of the conductivity of oil-impregnated insulation paper reinforced with different nano- $\mathrm{TiO}_{2}$ contents at different frequencies is shown in Figure 7 . In the test frequency, the four kinds of oil-impregnated insulation paper had similar variation trends, and the conductivity increased with increasing frequency. The conductivity decreased with increasing nano- $\mathrm{TiO}_{2}$ content. From $10^{-2} \mathrm{~Hz}$ to $10 \mathrm{~Hz}$, the conductivity of the four kinds of oil-impregnated insulation paper is significantly different. However, the conductivities of the four kinds of oil-impregnated insulation paper are very similar from $10 \mathrm{~Hz}$ to $10^{7} \mathrm{~Hz}$. As can be seen in Figure 8, the volume conductivity of oil-impregnated insulation paper is reduced with increasing nano- $\mathrm{TiO}_{2}$ content under a DC electric field. 


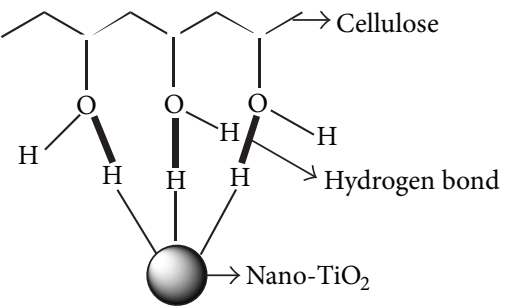

(a)

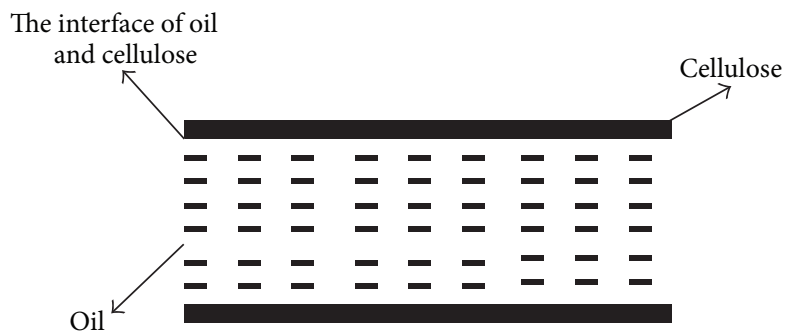

(b)

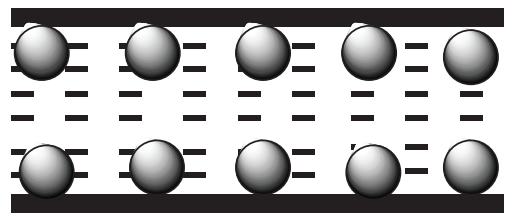

(c)

Figure 9: Structure of gap. (a) Interaction between cellulose and nano- $\mathrm{TiO}_{2}$; (b) oil gap; (c) oil gap reinforced by nano-TiO 2 .

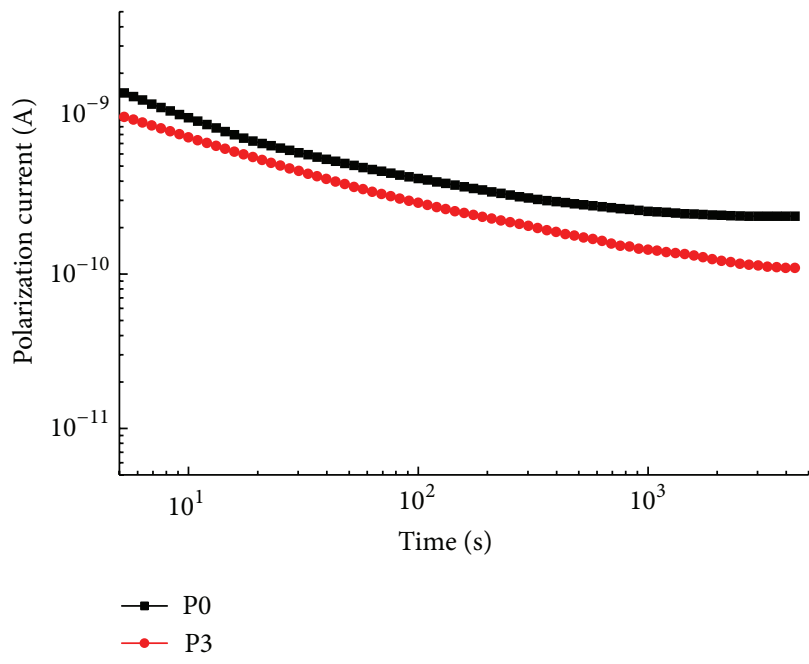

(a)

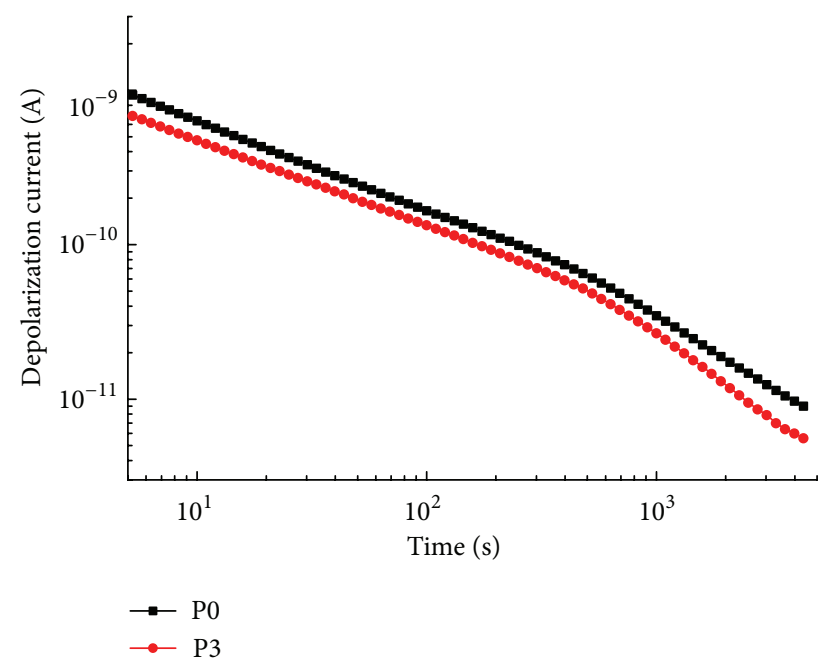

(b)

FIGURE 10: The polarization current and depolarizing current of oil-impregnated insulation paper.

Insulation paper is composed of cellulose, which is linked by hydrogen bonds. There are a large number of gaps in the interior of insulation paper; when the insulation paper is immersed in insulation oil, those gaps are filled with the insulation oil. Under an electric field, the breakdown first occurs in the weakest part. Because the electric field strength distribution of each part of composite insulation has an inverse correlation with relative permittivity, the relative permittivity of cellulose is higher than that of insulation oil and the breakdown strength of insulation oil is lower than that of cellulose. Therefore, those gaps that are filled with insulation oil in the interior of the oil-impregnated insulation paper are broken down first.

It is well known that electron is accelerated in the insulation oil more easily than in the cellulose. These electrons may develop into fast electrons, which possibly leads to the oil-impregnated insulation paper breakdown. When nano$\mathrm{TiO}_{2}$ is added to the insulation paper, it enters the interior of insulation paper and is present on the surface of cellulose. All the contact interfaces of cellulose and oil have the nano- $-\mathrm{TiO}_{2}$. As shown in Figure 9, one side of nano- $-\mathrm{TiO}_{2}$ is firmly attached to the cellulose surface and the other side is immersed in insulation oil. According to the literature [18], a large number of traps are likely generated because of nano- $\mathrm{TiO}_{2}$; these traps form a protective tape. When the fast electrons enter the protective tape, the fast electrons can be converted to slower electrons by repeated trapping and detrapping in the protective tape.

We measured the polarization current, depolarizing current, and trap characteristics of oil-impregnated insulation paper by the PDC and TSDC methods in order to understand the effect of $\mathrm{TiO}_{2}$ nanoparticles. Figure 10 shows the changes 


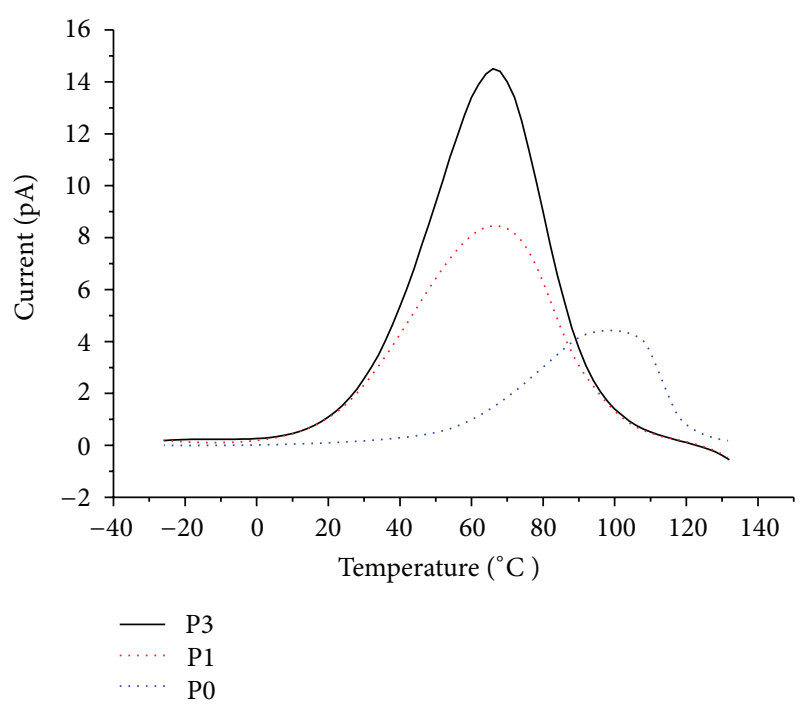

FIGURE 11: The results of thermally stimulated depolarization current measurement.

in the polarization current and depolarizing current with time. The polarization current and depolarizing current of oil-impregnated insulation paper reinforced with nano- $-\mathrm{TiO}_{2}$ both decrease. It is well known that the depolarization current from $1 \mathrm{~s}$ to more than $1000 \mathrm{~s}$ is mainly caused by interfacial polarization [19]. And the value of depolarization current is determined by the permittivity and conductivity of oil and cellulose on both sides of the interface. Now that the value is changed, it can be proposed that the permittivity and conductivity of oil and cellulose on both sides of the interface are changed because of nano- $\mathrm{TiO}_{2}$. The changes may be the reason why the permittivity and conductivity of oilimpregnated insulation paper reinforced with nano- $\mathrm{TiO}_{2}$ are changed.

As shown in Figure 11, the results of thermally stimulated depolarization current of oil-impregnated insulation paper reinforced with nano- $\mathrm{TiO}_{2}$ and oil-impregnated insulation paper are greatly different. The peak value of TSDC curve for P3 is 3.25 times that of P0. Since the peak value of TSDC curve is related to maximum trap density in a dielectric, P3 and P1 is assumed to have a higher trap density than the $\mathrm{P} 0$. The integration of TSDC over temperature gives the total number of trap charge released from the trap center. It is found that the total number of charge trapped in P3 and P1 are $6.10 \mathrm{nC}$ and $4.21 \mathrm{nC}$, respectively. But the total number of charge trapped in P0 is $1.96 \mathrm{nC}$. The peak position of P3 and $\mathrm{P} 1$ is the same; it can be proposed that the increased traps are generated because of nano- $\mathrm{TiO}_{2}$. These results demonstrate that the presence of $\mathrm{TiO}_{2}$ nanoparticles in the oil-impregnated insulation paper dramatically increases the electron trap density.

\section{Conclusions}

(1) The breakdown strength of oil-impregnated insulation paper is first increased and then decreased, with increasing nano- $\mathrm{TiO}_{2}$ content. $\mathrm{P} 3$ has the maximum breakdown strength of $61.78 \mathrm{kV} / \mathrm{mm}$. The value increased by $20.83 \%$ compared to $\mathrm{P} 0$.

(2) The relative permittivity, dielectric loss, and conductivity decreased with increasing nano- $\mathrm{TiO}_{2}$ content.

(3) The most likely reason that nano- $\mathrm{TiO}_{2}$ can affect the insulation properties of oil-impregnated insulation paper is because the addition of nano- $-\mathrm{TiO}_{2}$ can increase the total number of trap.

\section{Conflict of Interests}

The authors declare that they have no financial or personal relationship with any people or any organization that may inappropriately influence their work and there is no professional or commercial interest of any kind in all of the commercial entities mentioned in their paper.

\section{Authors' Contribution}

Ruijin Liao and Cheng Lv contributed equally to this study.

\section{Acknowledgments}

The authors would like to acknowledge support from the National Natural Science Foundation of China (51277187), the National Basic Research Program of China 973 Program (2009CB724505-1), and the National Natural Science Foundation of China (51107103).

\section{References}

[1] L. E. Lundgaard, W. Hansen, D. Linhjell, and T. J. Painter, "Aging of oil-impregnated paper in power transformers," IEEE Transactions on Power Delivery, vol. 19, no. 1, pp. 230-239, 2004.

[2] T. V. Oommen and T. A. Prevost, "Cellulose insulation in oil-filled power transformers-part II-maintaining insulation integrity and life," IEEE Electrical Insulation Magazine, vol. 22, no. 2, pp. 5-14, 2006.

[3] T. A. Prevost and T. V. Oommen, "Cellulose insulation in oilfilled power transformers-part I-history and development," IEEE Electrical Insulation Magazine, vol. 22, no. 1, pp. 28-35, 2006.

[4] V. Segal, A. Hjortsberg, A. Rabinovich, and D. Nattrass, "Experimental study of magnetic colloidal fluids behavior in power transformers," Journal of Magnetism and Magnetic Materials, vol. 215 , no. 2 , pp. 513-515, 2000.

[5] J. G. Huang, F. O’ Sullivan, M. Zahn, O. Hjortstam, L. A. A. Pettersson, and R. Liu, "Effects of nanoparticle charging on streamer development in transformer oil-based nanofluids," Journal of Applied Physics, vol. 107, no. 1, Article ID 014310, 2010.

[6] P. KopWansky, L. Tomco, and K. Marton, “The DC dielectric breakdown strength of magnetic fluids based on transformer oil," Journal of Magnetism and Magnetic Materials, vol. 289, no. 1, pp. 415-418, 2005.

[7] G. W. Lee, M. Park, J. Kim, J. I. Lee, and H. G. Yoon, "Enhanced thermal conductivity of polymer composites filled with hybrid filler," Composites A, vol. 37, no. 5, pp. 727-734, 2006. 
[8] C. P. Wong and R. S. Bollampally, "Thermal conductivity, elastic modulus, and coefficient of thermal expansion of polymer composites filled with ceramic particles for electronic packaging," Journal of Applied Polymer Science, vol. 74, no. 14, pp. 33963403, 1999.

[9] C. Y. Hsieh and S. L. Chung, "High thermal conductivity epoxy molding compound filled with a combustion synthesized AIN powder," Journal of Applied Polymer Science, vol. 102, no. 5, pp. 4734-4740, 2006.

[10] P. Bujard, G. Kuhnlein, S. Ino, and T. Shiobara, "Thermal conductivity of molding compounds for plastic packaging," in Proceedings of the IEEE 44th Electronic Components \& Technology Conference, pp. 159-163, May 1994.

[11] G. W. Lee, J. I. Lee, S. S. Lee, M. Park, and J. Kim, "Enhanced thermal conductivity of polymer composites filled with hybrid filler," Composites A, vol. 37, no. 5, pp. 727-734, 2006.

[12] P. Procter and J. Solc, "Improved thermal conductivity in microelectronic encapsulants," in Proceedings of the 41st Electronic Components \& Technology Conference, pp. 835-842, Atlanta, Ga, USA, May 1991.

[13] M. Ohashi, S. Kawakami, Y. Yokogawa, and G. C. Lai, "Spherical aluminum nitride fillers for heat-conducting plastic packages," Journal of the American Ceramic Society, vol. 88, no. 9, pp. 26152618, 2005.

[14] P. Pang and P. Englezos, "Application of pretreated ground calcium carbonate in mechanical pulp suspensions," Pulp and Paper Canada, vol. 104, no. 6, pp. 37-39, 2003.

[15] B. P. Lambert and J. Lowes, U.S. Patent 3873336, 1975.

[16] K. T. Wu, U.S. Patent 5599388, 1997.

[17] B. Thorp, "Engineered fillers: an agenda 2020 goal-to improve forest products industry economics, we must learn to leverage resources. One of those resources is engineered fillers," Solutions, vol. 88, no. 5, pp. 45-48, 2005.

[18] Y. F. Du, Y. Z. Lv, C. R. Li et al., "Effect of semiconductive nanoparticles on insulating performances of transformer oil dielectrics and electrical insulation," IEEE Transactions on Dielectrics and Electrical Insulation, vol. 19, no. 3, pp. 770-776, 2012.

[19] T. K. Saha and P. Purkait, "Investigation of polarization and depolarization current measurements for the assessment of oilpaper insulation of aged transformers," IEEE Transactions on Dielectrics and Electrical Insulation, vol. 11, no. 1, pp. 144-154, 2004. 

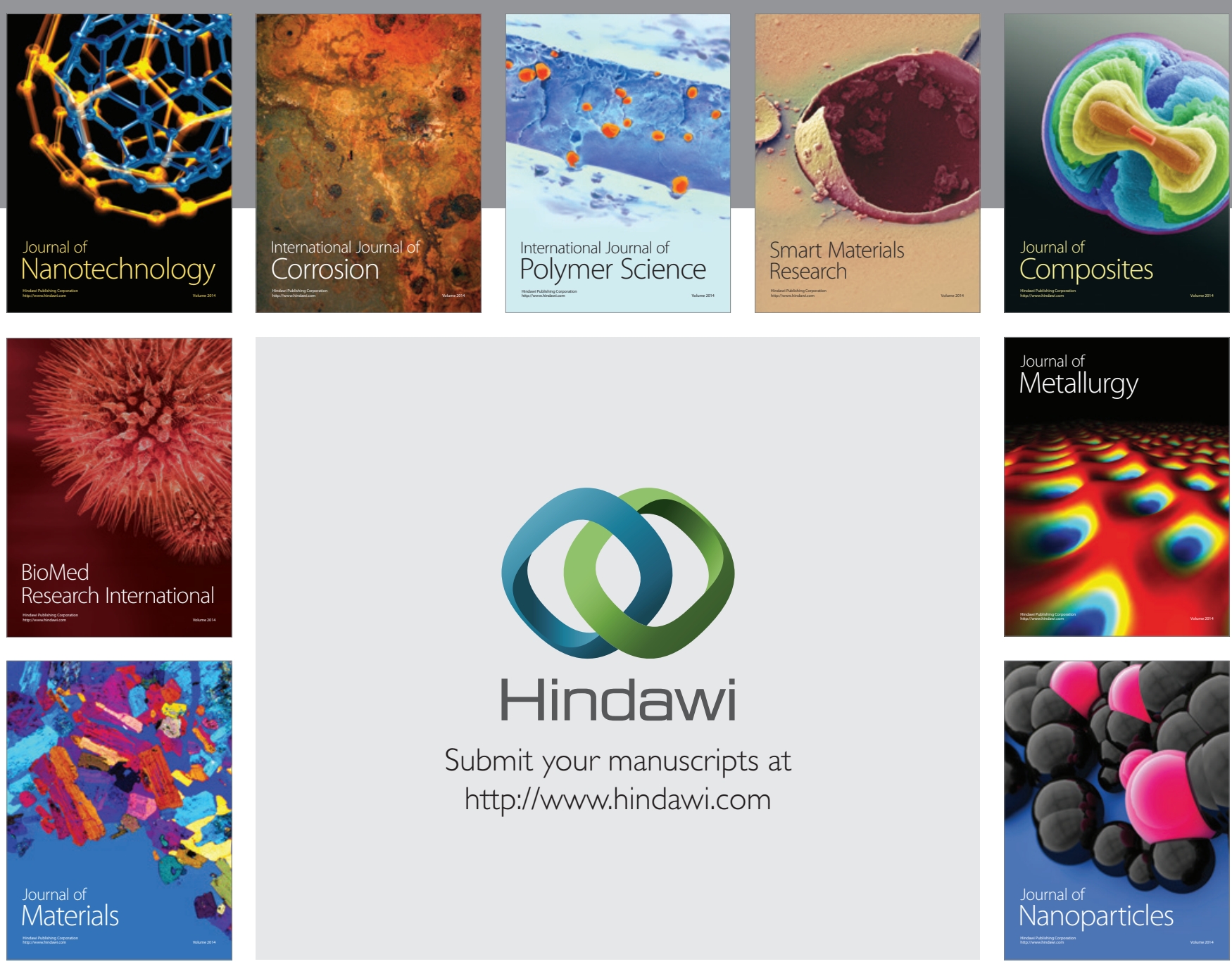

Submit your manuscripts at http://www.hindawi.com
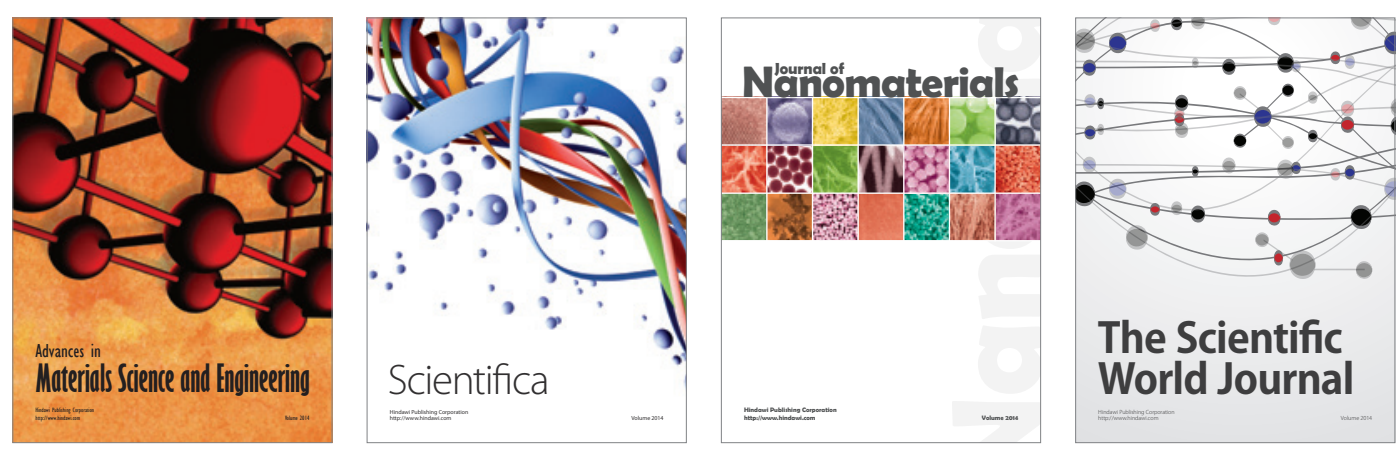

\section{The Scientific World Journal}
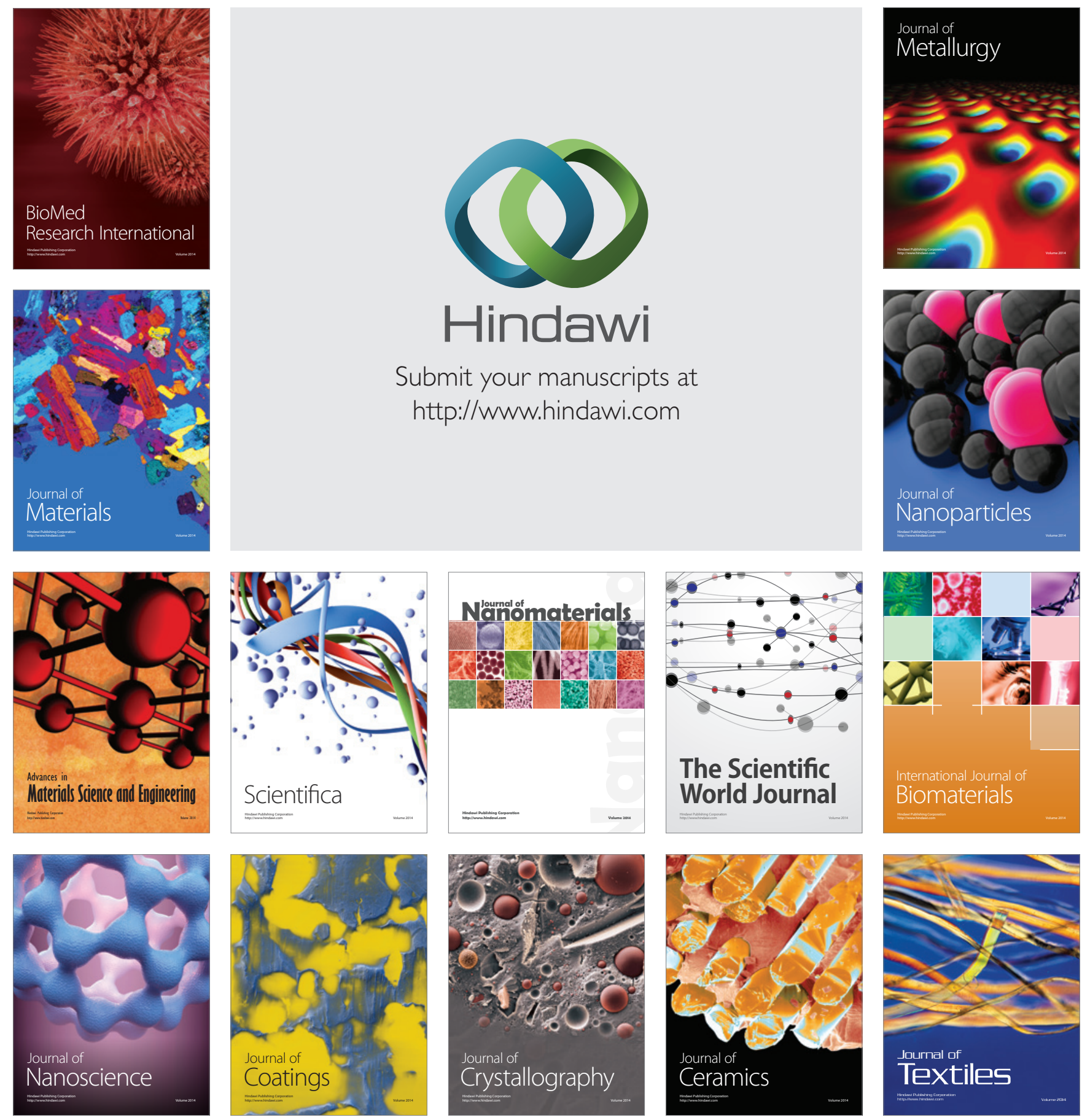